\title{
Neurolinguistic Approaches in Morphology a
}

\author{
Niels O. Schiller
}

Subject: Morphology, Neurolinguistics, Psycholinguistics Online Publication Date: Apr 2020

DOI: $10.1093 /$ acrefore/9780199384655.013.601

\section{Summary and Keywords}

Neurolinguistic approaches to morphology include the main theories of morphological representation and processing in the human mind, such as full-listing, full-parsing, and hybrid dual-route models, and how the experimental evidence that has been acquired to support these theories uses different neurolinguistic paradigms (visual and auditory priming, violation, long-lag priming, picture-word interference, etc.) and methods (electroencephalography [EEG]/event-related brain potential [ERP], functional magnetic resonance imaging [fMRI], neuropsychology, and so forth).

Keywords: morphologically complex words, inflection, derivation, compounding, language comprehension, language production, morphological processing, visual priming, picture-word interference, long-lag priming, naming latencies, EEG/ERP, fMRI

\section{Introduction}

Neurolinguistics, as well as psycholinguistics, provides experimental approaches to linguistic phenomena. Both are concerned with language processing in the human mind. While the boundary between neurolinguistics and psycholinguistics is not always straightforward, neurolinguistics-more than psycholinguistics-is usually associated with at least the following two aspects: language processing in brain-damaged individuals and neuroimaging (and other brain monitoring/manipulation techniques) of brain functions associated with language processing (see De Zubicaray \& Schiller, 2019).

This article will take a neurolinguistic perspective on morphological processing. It will mainly be concerned with the question of how morphologically complex words are represented and processed in the mental lexicon. The mental lexicon is part of our long-term memory where the meanings and forms (phonology, orthography, and/or gestures) are stored (see Schiller \& Verdonschot, 2015, for a review). It is important to specify the basic units (e.g., sounds/letters, phonemes/graphemes, morphemes, etc.) in terms of which lexical entries are organized in the mental lexicon because the architecture of the language processing system will partially depend on the units of representation. Moreover, it is necessary to study the representation and processing of morphologically complex 
words to be able to dissociate word and morpheme-based organization (Marslen-Wilson, Tyler, Waksler, \& Older, 1994).

There are a number of interesting questions when it comes to the representation and processing of morphologically complex words. For instance, are all words (inflected, derived, and compounded) stored in their full form? Consider words like bird, birds, birdy, birdhouse and jailbird. It is clear that we need to have the concept of a (generic) bird stored in our mental lexicon together with its pronunciation (/bird/) and spelling (B-I-R-D) (or the corresponding gestures). However, what about the inflected form birds or the derived form birdy. Is the plural form birds also stored in the mental lexicon or are words that form their plural with -s rather composed on the basis of their stem (i.e., bird) and the plural suffix -s? And what about compound forms like birdhouse and jailbird-are they stored in the lexicon or composed by fitting two stems together? In the case of birdhouse, combining two stems, that is, bird and house, would be enough to arrive at the compound birdhouse because its meaning is transparent. If we know what a bird is and we know what a house is, we can derive the meaning of birdhouse, that is, a house for birds. However, in the case of jailbird, this does not work. Therefore, storage in the lexicon seems necessary. In fact, this also holds for derived words: whereas the meaning of inflected words is always predictable, this is not always the case for derived words. According to Schreuder, Grendel, Poulisse, Roelofs, and Van de Voort (1990), decomposition for inflected forms is more likely than for derived forms because the meaning of a derived word is not simply the sum of their parts. Are some morphologically complex words stored while others are composed? Let us first review the most prominent models in the literature.

\subsection{Full-Listing of Morphologically Complex Words}

Full-listing models (Butterworth, 1983, 1989; Mannelis \& Tharp, 1977) propose that morphologically complex forms are stored as full forms in the mental lexicon. That is, forms like bird, birds, birdy, birdhouse, jailbird, and so forth would all have their own lexical entry and not be decomposed into their constituent morphemes, that is, under a full-listing hypothesis there is no room for morphology. From a computational point of view such a model would be simple in terms of representation of lexical entries because all full forms would be represented in the lexicon. The access to all of these forms would presumably be more complicated. Another potential disadvantage would be that listing all forms is costly in terms of storage. Think, for instance, about highly inflected languages such as German with a full-fledged case system in the nominal system (e.g., der große Tisch ${ }_{\mathrm{NOM}}$ $\mathrm{SG}$ 'the big table', des großen Tisches ${ }_{\mathrm{GEN} \mathrm{SG}}$, dem großen Tisch DAT SG$_{\text {, den großen Tisch }}$ ACC

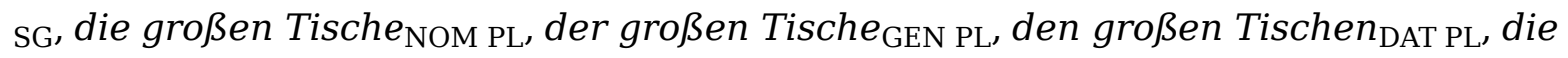
großen Tische ACC $_{\mathrm{PL}}$ ) and person inflection in the verbal system (e.g., ich gehe 'I walk', du gehst, er/sie/es geht, wir gehen, ihr geht, sie gehen; ich ging 'I walked', du gingst, er/sie/ es ging, wir gingen, ihr gingt, sie gingen; ich bin gegangen 'I have walked', du bist gegangen, er/sie/es ist gegangen, wir sind gegangen, ihr seid gegangen, sie sind gegangen, etc.). Also, think about agglutinative languages such as Finnish, Turkish, Inuktitut, or Nahuatl, in which words may contain different stems and affixes that together determine the meaning of a word. In Finnish, for instance, one can easily generate dozens if not 
hundreds of words from the same stem. Full-listing models become increasingly inefficient in languages like these. Sub-symbolic non-morphological representations as posited in some computational approaches in fact fall into the class of full-listing models as well (Seidenberg \& Gonnerman, 2000).

\subsection{Full-Parsing of Morphologically Complex Words}

In contrast to full-listing models, full-parsing or decompositional models of representation assume that the stem(s) and affixes of morphologically complex words are stored separately. That is, the stem bird would be stored as would all the affixes of the English language, for example, the plural -s affix, the derivational affix -y, and so on. To construct the word form birds, the stem bird plus plural affix -s need to be activated and put together yielding birds. Similarly, bird plus the derivational affix -y yield the word birdy. A full-parsing or decompositional model has the advantage of being less costly in terms of storage as affixes only have to be represented once. On the other hand, full-parsing models are computationally demanding as morphologically complex words require computational processes to activate the correct word form from the mental lexicon. According to full-decompositional models, complex word recognition always involves morpheme-based processing (e.g., Stockall \& Marantz, 2006; Taft, 2004).

\subsection{Dual-Access of Morphologically Complex Words}

Finally, dual-access models are hybrid models in which, for instance, irregular words are accessed directly as fully listed forms whereas regular complex words are accessed indirectly and decomposed into their underlying morphemes (Clahsen, 1999; Isel, Gunter, \& Friederici, 2003; Pinker, 1999). Different mechanisms may be at work for different kinds of morphological processes as well. For instance, Bozic and Marslen-Wilson (2010) argue that inflection and derivation may have distinct neurobiological processing correlates that may be captured in a dual-access model.

It should be noted that there are still other views around in the literature such as the discrimination learning model using cues based on sub-lexical orthographic features and semantics (see Milin, Feldman, Ramscar, Hendrix, \& Baayen, 2017). This model demonstrates the superiority of discrimination-based predictors over lexical-distributional predictors and does not support the (obligatory) segmentation of words into morphemes.

\section{Morphological Processes in Language Com- prehension}

This article will be on morphological processing in language comprehension and production. Although the focus will be on compound production, the article will also discuss other types of morphological processing such as inflection and derivation, also in compre- 
hension. For a more extensive discussion of morphological processing in comprehension, please see Schiller and Verdonschot (2019).

\subsection{Comprehension of Morphologically Complex Words: The Case of Inflected Words}

One possibility to investigate neural activity in language processing is through so-called violation paradigms (Kutas \& Hillyard, 1980, 1984). In the morphological violation paradigm (e.g., Penke et al., 1997; Rodriguez-Fornells, Clahsen, Lleó, Zaake, \& Münte, 2001), correct and incorrect forms of morphological combinations (e.g., verbs plus inflectional suffixes) are embedded into word lists or sentences. Event-Related Brain Potential (ERP) signals may demonstrate whether or not participants consider morphological combinations as violating their morphological rules.

In an ERP study using a morphological violation paradigm, Penke et al. (1997) hypothesized that if all morphologically complex forms are stored, the brain should not react differently to regular and irregular forms. They tested German participles such as gebaut ('built'; regularly ending in -t) and gelaufen ('run'; irregularly ending in -en). Also, if all morphologically complex forms are decomposed into their constituent morphemes regardless of their regularity status, no differences should be found in neural responses. However, Penke et al. obtained results that demonstrated differential processing for regularly and irregularly formed participles. Only incorrect irregular participles yielded a left anterior negativity (LAN) effect as compared to correctly formed irregular participles; no such difference was found for regular participles. Since Penke et al.'s results showed that regularly and irregularly inflected words are processed differently, this supports the dualmechanism model. In this model, irregularly inflected words are stored in the lexicon and accessed as full forms during processing, while regularly inflected words are decomposed into stems and inflectional affixes. This finding was roughly replicated by Rodriguez-Fornells et al. (2001) in Catalan using conjugated verbs. They found a LAN effect for stem violations but not for incorrectly inflected participles. However, unlike Penke et al., they also obtained a P600 for both stem violations and incorrectly formed participles. Note, however, that Rodriguez-Fornells et al. (2001) used a different paradigm, namely, embedding the stimuli in short stories. Smolka, Khader, Wiese, Zwitserlood, and Rösler (2013) extended the studies by Penke et al. and Rodriguez-Fornells et al. in a visual priming paradigm using German first person singular present verb forms as primes (e.g., laufe , 'I run') and participles (e.g., gelaufen, 'run') as targets to investigate the existence of graded neural responses depending on the regularity of the verb. In particular, their crucial manipulation included semi-irregular participles with a regular stem but an irregular inflectional suffix (e.g., gelaufen) and fully irregular participles (e.g., getrunken, 'drunken'; prime: trinke 'I drink'). Smolka et al. (2013) obtained graded behavioral and ERP patterns that were dependent on verb regularity: regular participles yielded the largest and most widely distributed effects, irregular participles small and the least widely distributed effects, and semi-irregular participles produced an effect and distribution in between the 
former two. These results argue against a dichotomous (regular/irregular) dual route model and favor a continuous system for processing inflected verbs in German.

\subsection{Comprehension of Morphologically Complex Words: The Case of Derived Words}

A typical way to study word derivation and whether or not a derived word is processed by accessing the stem morpheme is by using priming paradigms in which the processing of a derived word is measured relative to the presentation of a related versus unrelated prime. For instance, Tyler, Marslen-Wilson, and Waksler (1993) demonstrated the importance of a semantic relationship between base words and derived forms (casual is primed by casually but not by casualty due to a shared semantic relationship between the former but not the latter prime with the target base morpheme). Based on these previous results, Smolka, Gondan, and Rösler (2015) investigated semantically-related derivations in German verbs using the electroencephalography (EEG)/event-related brain potential (ERP) technique. In particular, in an overt visual priming experiment, ERPs were obtained for target verbs (e.g., sprechen 'to speak') which were primed by semantically related verbs (e.g., reden 'to talk'), morphologically and semantically related verbs (e.g., ansprechen 'to address'), and morphologically related but semantically unrelated verbs (e.g., entsprechen 'to match'), orthographically related verbs (e.g., sprengen 'to blow'), and completely unrelated verbs (e.g., biegen 'to bend'). Looking at the N400 (an ERP component occurring about 400-600 ms after target onset typically attenuated by a semantic relationship between prime and target), in line with previous results and expected, Smolka et al. found an N400 component that was strongly attenuated for semantically related verbs compared to unrelated verbs (e.g., reden-sprechen vs. biegen-sprechen). Additionally, semantically transparent derivations showed priming (e.g., ansprechen-sprechen vs. biegen-sprechen) but remarkably also semantically opaque derivations showed N400 attenuation (e.g., entsprechen-sprechen vs. biegen-sprechen). Moreover, Smolka et al. reported that the N400 attenuation for opaque derivations was as strong as that for semantically transparent derivations. Note that earlier studies did not obtain any priming for their opaque conditions (e.g., Kielar \& Joanisse, 2011). Smolka et al.'s findings indicate that the structure for German verbs refers to the base form irrespective of semantic composition.

\subsection{Comprehension of Morphologically Complex Words: The Case of Compounds}

While inflectional and derivational processes have received relatively much attention, only few neurolinguistic studies have focused on the comprehension of compounds (e.g., Koester, Gunter, Wagner, \& Friederici, 2004; Koester, Gunter, \& Wagner, 2007). In an event-related brain potential (ERP) study, Koester et al. (2004) carried out several experiments in which the grammatical gender agreement between a determiner and the modifier as well as the head in German compounds was manipulated while the electroencephalography (EEG) was recorded. Although only the head is morphosyntactically significant in German, both the head and the non-relevant modifiers elicited a left-anterior neg- 
ativity (LAN effect) in incongruent gender-determiner conditions compared to congruent ones. According to Koester et al., their findings suggest that the internal morphological structure of German compounds is processed during language comprehension.

Fiorentino and Poeppel (2007) employed a visual lexical decision task to provide evidence that lexicalized English compounds are decomposed into morphological constituents.

They used an electrophysiological brain-imaging method called magnetoencephalography (MEG) and compared the processing of lexicalized compounds (e.g., teacup) with lengthmatched monomorphemic control words (e.g., throttle). Their results demonstrated faster behavioral responses (RTs) and earlier latencies of the M350 component, indicating lexical access, for compounds compared to monomorphemic words. Fiorentino and Poeppel interpreted their finding as reflecting constituent activation for the lexicalized compounds. In a later study, Fiorentino, Naito-Billen, Bost, and Fund-Reznicek (2014) replicated the behavioral results of Fiorentino and Poeppel (2007) and presented electrophysiological evidence for morpheme-based processing of both lexicalized (e.g., teacup) and novel (e.g., tombnote) English compounds presented visually. In the 275-400 ms time window effects of lexicality emerged, with novel words yielding more negative-going responses than lexicalized words broadly. Fiorentino et al. argue that their study provides evidence for morpheme-based processing of lexicalized and novel English compound words, consistent with across-the-board decomposition approaches.

\section{Morphological Processes in Language Pro- duction}

Language production involves the conversion of thoughts into articulation. This process starts with what is called conceptualization, that is, the encoding of meaning into a preverbal message. Conceptualization precedes form encoding, that is, lexical access plus phonological-phonetic encoding (in case of speech production; for the written and gestural modality encoding processes obviously differ), also called formulation. The final step in the process of producing speech is articulation, or the execution of neuro-phonetic motor programs.

Most models of language production (i.e., Caramazza, 1997; Dell, 1986, 1988; Levelt, 1989; Levelt, Roelofs, \& Meyer, 1999) would agree that these steps are necessary for producing words; however, models diverge when it comes to the exact timing and timecourse of processing. Moreover, how morphologically complex words are processed is not completely clear yet. A decomposed representation would avoid duplication of the representation of the individual constituents. In fact, Bien, Baayen, and Levelt (2005) support this position with data from a production naming study manipulating the lexical frequency of compounds and their constituents. Their study demonstrated that the frequencies of the constituents but not of the whole compound predicted naming latencies (see, however, also Janssen, Bi, \& Caramazza, 2008). 
Speech error research also provided evidence for morphological decomposition. For instance, errors like slicely thinned instead of thinly sliced (Stemberger, 1985) or getting your model renosed instead of getting your nose remodeled (Fromkin, 1971) were taken as evidence suggesting that morphologically complex words are composed from separate constituents rather than produced as holistic units. In fact, Garrett $(1975,1980)$ assigned these so-called stranding errors to what he called the positional level of representation, that is, the level at which content words are inserted into pre-specified syntactic slots and phonologically encoded. In Garrett's theory, the positional level follows a functional level at which content words are retrieved on the basis of their function in a sentence. Affixes are part of the positional level, that is, they are part of the slots. When two content words are exchanged by accident, that may result in stranding errors such as slicely thinned.

Apart from stranding errors, some blending errors also demonstrate a potential role for morphemes being a unit of processing. Take for instance the misspeaking "They misunderestimated me", an original Bushism (George W. Bush, November 6, 2000, Bentonville, Arkansas). This blending error, presumably originated from "misunderstood" and "underestimated" merged together, beautifully preserved the underlying morphological boundaries. This resulted in the error "mis-under-estimate-d" but not "munderestimated" or "misundestimated."

Word encoding is known to be a serial process: phonemes at the beginning of words are planned earlier than phonemes at the end (Meyer, 1990, 1991). Morphologically complex words are also planned incrementally. Roelofs (1996), for example, tested the naming latencies of morphologically complex, pre-fixed words under two conditions using the preparation paradigm, that is, in homogeneous sets, when the first morpheme overlapped for all words in the set (e.g., bij in bijvak 'subsidiary subject', bijrol 'supporting role', bijnier 'kidney'), compared to heterogeneous sets, when the first morpheme was different for all words in the set (e.g., bijvak 'subsidiary subject', herkomst 'origin', najaar 'fall'). A mean preparation effect of $74 \mathrm{~ms}$ was obtained, that is, the word bijvak was produced significantly faster in the homogeneous condition than in the heterogeneous condition because participants could prepare the first morpheme of each word in the homogeneous set. To disentangle morphological from phonological overlap, Roelofs (1996) also tested words with the same amount of phonological overlap but without morphological overlap. For instance, the word bijbel 'bible' produced in a homogenous set (e.g., bijbel 'bible', bijna 'almost', bijster 'loss') compared to a heterogeneous set (e.g., bijbel, hersens 'brain', nader 'further'). This phonological overlap yielded a significantly lower facilitation effect of $30 \mathrm{~ms}$ than the effect that resulted from morphological overlap. Since non-initial morphemes (e.g., boom in stamboom 'pedigree', spoorboom 'barrier', hefboom, 'lever') did not lead to any preparation effect, Roelofs (1996) concluded that language production proceeds incrementally from left to right and that morphemes are used as production units.

A last piece of evidence I would like to present in favor of morphological processing in language production comes from a neuropsychological patient. Some dysgraphic patients, that is, patients with a spelling deficit, present with damage to their graphemic 
buffer. The graphemic buffer is "a working memory system which temporarily holds graphemic representations for subsequent, more peripheral processes (e.g., allophonic conversion)" (Caramazza \& Miceli, 1990, pp. 257-258). One characteristic of graphemic buffer patients is that they produce more spelling errors toward the end of words than at the beginning. Schiller, Greenhall, Shelton, and Caramazza (2001) reported a graphemic buffer patient, PB, who presented with an interesting pattern. Although PB's overall error pattern corresponded to the pattern characteristic for graphemic buffer patients, her spelling errors in morphologically complex words such as compounds showed a different pattern, that is, she presented with an increasing error pattern for each separate morpheme. For instance, in a compound word such as nightstand she would make significantly fewer spelling errors $(79.6 \%$ correct) in the first few letters of the second morpheme (e.g., $s$ and $t$ ) compared to the last few letters (57.4\% correct) of the first morpheme (e.g., $h$ and $t$ ), although they occur earlier in the word. In other words, it seems as if this patient treats the constituents of the compound as separate words that are buffered separately (see Figure 1).

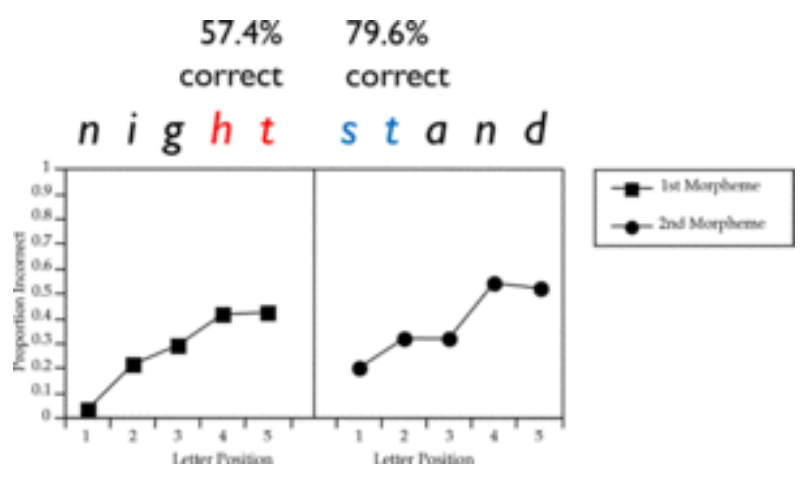

Figure 1. Distribution of spelling errors in compound words.

Data from patient PB described in Schiller et al. (200 1).

\subsection{Production of Morphologically Complex Words: The Case of Com- pounds}

A particular case of morphologically complex words are compounds (Libben, 2006). Compound words consist of at least two word stems put together. Remember the previously mentioned examples birdhouse and jailbird-both are noun-noun compounds, but in the former, bird is the modifier, whereas in the latter it is the head. However, compounds can be much longer and consist of many more stems, for example, Sonntagsnachmittagsspaziergang; example from (Libben, 2006).

In the following, I will review a number of studies investigating the production of nounnoun compounds using the so-called long-lag priming paradigm. In this paradigm, participants are presented with words and pictures, one at a time, and are requested to name each stimulus as fast as possible. Stimuli are simplex and complex words. Unbeknown to the participants, some stimuli are primes, some are targets, and some are fillers. The 
minimal interval between a prime and a target is seven items. That is why this paradigm is called long-lag priming: in fact, the time between the presentation of the prime and the presentation of the target is on average at least around 30 seconds, that is, short-term priming effects such as obtained in masked priming, for instance, do not survive this interval.

Zwitserlood, Bölte, and Dohmes (2000, 2002) observed significant morphological priming effects in a number of picture naming experiments carried out in German. For instance, target pictures (e.g., Blume, 'flower') were named significantly faster when preceded by a morphologically related word such as Blumen ('flowers') as compared to an unrelated word (Drachen 'dragon'). Although Blume and Blumen overlap not only morphologically but also semantically and phonologically, the facilitation effect cannot be explained by those factors (see also Feldman, 2000). When the same target pictures were combined with semantic (e.g., Nelke 'dianthus') and phonological (e.g., Bluse 'blouse') distractor words in a picture-word interference paradigm, they showed semantic interference and phonological facilitation, respectively, but not in long-lag priming. In other words, semantic and phonological priming effects are short-lived and not effective after intervals of a series of intervening trials. Zwitserlood and colleagues suggested that the observed facilitation effect arises at the word form level where prime (e.g., Blumen) and target (e.g., Blume) activate the same representation, namely the morpheme blume. Interestingly, all morphological priming effects (derived: blumig 'flowery'-Blume 'flower'; inflected: Blumen 'flowers'-Blume; compound: Blumentopf 'flowerpot'-Blume) using the long-lag paradigm are approximately in the same ball park, that is, $30-40 \mathrm{~ms}$ in magnitude. Position of the morphemic overlap (e.g., Blumentopf-Blume or Topfblume 'potted flower'-Blume) did not play any role for the morphological priming effect (Zwitserlood et al., 2002).

In a follow-up study, Dohmes, Zwitserlood, and Bölte (2004) tested three conditions in a long-lag priming paradigm, that is, semantically transparent (e.g., Buschrose 'bush rose'-Rose), semantically opaque (e.g., Gürtelrose 'shingles'-Rose) and phonologically related (e.g., Neurose 'neurosis'-Rose) to disentangle semantic, phonological, and morphological effects. Significant priming effects, as measured relative to an unrelated condition, were demonstrated only for the morphologically related primes, whether or not they were semantically transparent. Morphological priming effects in word production seem to be largely independent of semantics (see also Gumnior, Bölte, \& Zwitserlood, 2006) and phonology (see also Kolan, Leikin, \& Zwitserlood, 2011).

\subsubsection{Compound Production: Behavioral and Electrophysiological Data}

Based on the studies by Zwitserlood and her colleagues Koester and Schiller (2008) designed a study in Dutch in which they not only measured behavioral data (i.e., picture naming latencies) but also electroencephalography (EEG) data. They employed two sets of materials: one in which they compared the effect of semantically transparent (e.g., eksternest 'nest of a magpie') and semantically opaque (e.g., eksteroog 'corn') primes on the naming of the target (e.g., ekster 'magpie'). Compared to an unrelated condition, both morphologically related primes yielded significant priming effects, again between $30 \mathrm{~ms}$ and $40 \mathrm{~ms}$ in magnitude. Furthermore, there was no statistically significant difference be- 
tween the conditions, that is, the semantically transparent and the semantically opaque condition yielded equal morphological priming. Therefore, it seems that the effect does not have a semantic basis.

The second set of materials compared semantically transparent (jaszak 'coat pocket') with phonologically related (jasmin 'jasmine') primes on the naming of the target (jas 'coat'). Again, compared to an unrelated condition, the morphologically related condition yielded a significant priming effect, but not the phonologically related condition. That is, the morphological priming effect is presumably not due to form overlap either. Therefore, Koester and Schiller (2008) argued that the effect arises at a level of morphological processing. This replicates the work of Zwitserlood and colleagues in German (2000, 2002; Dohmes et al., 2004). However, the Koester and Schiller (2008) study goes beyond the work of Zwitserlood and colleagues because it adds the electrophysiological dimension.

EEG (and its derivative ERP, Event-Related Potential) with its high time resolution in the millisecond range is the method of choice when it comes to the investigation of timecourse issues regarding language comprehension and production. EEG monitors and records brain signals non-invasively through surface electrodes that pick up on brain electrical activity on the scalp. The signal that is picked up is mostly post-synaptic activity of apical dendrites of large groups of pyramidal cells in the cortex that fire synchronously. Due to their robustness, non-invasiveness, and relative easiness of acquiring and analyzing data (as compared to functional magnetic resonance imaging [fMRI]), ERPs have become one of the main methods in neurolinguistic research. For further background information about the EEG technique and its application in language research the reader is referred to a recent overview by Leckey and Federmeier (2019).

Koester and Schiller (2008) found that the ERPs mirrored their behavioral results perfectly. For the first set of materials, both the semantically transparent and the semantically opaque condition yielded a reduced N400 effect. That is, the unrelated condition was significantly more negative than the two morphologically related conditions in the time-window 350-650 ms after picture onset. For the second set of materials, the semantically transparent condition yielded a priming effect, whereas the phonologically related condition did not. In fact, the latter condition did not differ from the unrelated condition. Taken together, the ERPs supported the behavioral data in that reduced N400 effects were only obtained when there was a morphological relationship between primes and targets-semantic transparency/opaqueness and/or phonological relationship did not influence this morphological priming effect. Koester and Schiller (2008) interpreted the N400 effect as reflecting facilitation in processing morphologically related words in a picture naming task.

Indefrey and Levelt (2004; see also Indefrey, 2011), presented a meta-study on the neurocognitive time course of speech production. Analyzing 80 studies including a speech production task and either electrophysiological (e.g., EEG/ERP, magnetoencephalography [MEG]) or neuroimaging (e.g., fMRI, positron emission tomography [PET]) measures, they draw a neo-cortical road map of the speech production process. Indefrey and Levelt esti- 
mated that semantic or conceptual processing begins approximately $175 \mathrm{~ms}$ after a target picture is presented (for naming). Around 75 ms later, that is, 250 ms after picture onset, the concept's lemma is selected as part of lexical access. Form encoding starts about another $80 \mathrm{~ms}$ later, or about $330 \mathrm{~ms}$ after picture presentation. Within word form encoding, morphological encoding is the first process, followed by prosodic and phonological encoding. The onset of the N400 effect in the Koester and Schiller (2008) study is very similar to the estimated onset of morphological encoding. Note that the estimates by Indefrey and Levelt (2004) are based on a picture naming latency of $600 \mathrm{~ms}$. Koester and Schiller (2008) scaled the onset of morphological encoding to the average response latency in their study (approximately $650 \mathrm{~ms}$ ) and obtained an estimate of $358 \mathrm{~ms}$ for the beginning of morphological encoding. This value is very close to the onset of the N400 effects in both stimulus sets. Therefore, because the observed N400 effects occur relatively late (i.e., 350-650 ms after picture onset) in the course of processing, presumably they mark the stage of morphological encoding that forms part of word form encoding.

\subsubsection{Compound Production: Neuroimaging Data}

Functional Magnetic Resonance Imaging (fMRI) is also a noninvasive method to monitor brain activity-just like electroencephalography (EEG)/event-related brain potential (ERP) -however, it is based on a completely different principle, namely the blood oxygen metabolism. When neurons are active, they consume oxygen, which is delivered by blood transported through vessels. The neural activity is measured by the so-called Blood Oxygenation Level Dependent (BOLD) signal. That is, fMRI does not directly measure neural activity, however, there is a strong correlation between neural activity and oxygen consumption. It takes a couple of seconds for the oxygen to arrive where it is needed. Due to its nature, fMRI has a lower time resolution than electrophysiological methods like EEG/ ERP, although possibilities have been developed to reduce the time resolution from the range of seconds. At the moment, fMRI is the most widely used neuroimaging technique, and it allows a powerful window on the neurobiology of language. For further information on the details of fMRI, the reader is referred to the recent overview chapter by Heim and Specht (2019).

Although Indefrey and Levelt (2004) came up with a neo-cortical road map of the speech production process, the neuroanatomical correlates of morphological priming remain controversial. Word-form encoding processes (including phonological code retrieval) have been localized in the left posterior superior and middle temporal gyri (Indefrey \& Levelt, 2004). One may predict that morphological information should affect neural activity in the left posterior superior and middle temporal gyri because morphological encoding is the first sub-stage of word form retrieval.

However, other researchers found different areas to be activated in tasks involving morphological processing. For instance, Bozic and Marslen-Wilson (2010) reported different brain areas involved in processing of rule-based morphology such as inflection (i.e., a leftlateralized fronto-temporal subsystem) compared to lexicalized morphology such as found in derived words. In other words, they argue for different neurobiological correlates for 
inflection versus derivation. The morphological processing involved in compounds may activate still other underlying neural areas.

In a follow-up study to their 2008 report, Koester and Schiller (2011) replicated and extended their previous study. Using exactly the same materials and design, they replicated their previous behavioral findings, that is, significant morphological priming effects, both in the transparent (though only marginally significant for the second set of materials) and the opaque conditions and no effect for phonologically related prime-target pairs. This result supports the claims made in the Koester and Schiller (2008) study.

The authors extended their previous study by including fMRI data. In a blocked design, primes and targets were presented one-by-one. First of all, they identified the so-called task network of language production in the brain (see Koester \& Schiller, 2011, Fig. 2; see also Spalek \& Thompson-Schill, 2008). The analysis of the neuroimaging data also revealed several significant contrasts of activation. For instance, the contrast morphologically primed versus unrelated condition in the first set of materials revealed one cluster in the left inferior frontal gyrus (LIFG) that was marginally significant on the cluster level. Calculation of effect sizes demonstrated that both the morphologically transparent and the opaque priming conditions elicited a stronger activation compared with the matched, unrelated condition. Other clusters of activation did not approach the cluster-size threshold.

However, Koester and Schiller (2011) computed further contrasts in order to check that there are voxels in the brain that are differentially activated by the morphologically transparent and opaque conditions. That was not the case, that is, a direct comparison between the transparent and the opaque condition revealed no brain area that was differentially activated by these two conditions. However, in addition a so-called conjunction analysis (Nichols, Brett, Andersson,Wager, \& Poline, 2005; Price \& Friston, 1997) was carried out to identify the area of activation present for both the transparent and opaque conditions. This conjunction analysis demonstrated shared effects only for a relatively small area in left BA 47 (see Koester \& Schiller, 2011, Fig. 5). The same contrasts for the second set of materials did not show any significantly activated cluster, that is, the morphologically transparent and the form-related condition contrasted with the unrelated condition did not reveal any significantly activated neural area.

Koester and Schiller $(2008,2011)$ investigated the functional neural correlates of morphological processing in overt language production. They replicated earlier behavioral results from German by Zwitserlood and her colleagues (Dohmes et al., 2004; Zwitserlood et al., 2000, 2002) in the Dutch language. Moreover, they extended the German findings to the area of electrophysiology and neuroimaging. Reduced N400 effects were demonstrated in exactly the same conditions, which yielded significant morphological priming. Interestingly, those conditions revealed significantly more activation than the unrelated condition in a relatively small part of area BA 47 in the left hemisphere. The increased activation in this particular brain area may be responsible for the enhanced and facilitated 
processing of target picture names in morphologically primed (relative to unrelated) conditions reflected by faster response times and reduced N400 effects.

\subsubsection{Compound Production: Behavioral Data in L1 and L2}

Multilingualism is a common phenomenon in the world we live in (Grosjean, 2010). Many people know more than one language and regularly speak in another language. How do we manage to speak in our second language without interference from our first language? One idea is that we actively inhibit the non-target language. So-called inhibitory control models (Green, 1998) claim that a specific cognitive control system monitors the language-specific processing. More specifically, this mechanism activates the target language and suppresses the non-target language.

Verdonschot, Middelburg, Lensink, and Schiller (2012) used the long-lag morphological priming paradigm to test whether or not the morphological priming described would survive the active inhibition. Two conditions were created: one in which bilingual Dutch-English speakers name items in Dutch (i.e., the non-switch condition) and one in which the same participants name items in English, in between naming the prime and the target in Dutch (i.e., the switch condition). One scenario in the switch condition is that the Dutch prime is being actively suppressed such that it will lose its effect on the production of the target. In that case, no morphological priming effect should occur in the switch condition whereas in the non-switch condition the effect reported in Koester and Schiller (2008, 2011) should be replicated.

Target stimuli were largely similar to the target items of Koester and Schiller (2008, 2011; 70\% overlap). Verdonschot et al. (2012) tested three priming conditions: a morphologically transparent (kerkklok, 'church bell'), a morphologically opaque (klokhuis, 'apple core'), and an unrelated prime (for the target klok 'clock'). In the non-switch condition, when Dutch-English bilinguals named primes, targets, and fillers in Dutch, significant morphological priming effects were obtained for both the transparent and the opaque condition, with no significant difference between these conditions. This did not come as a surprise as this is the third replication of a stable effect: both Koester and Schiller (2008) and Koester and Schiller (2011) have reported similar effects with largely overlapping materials. In fact, the main variable that changed in Verdonschot and colleagues is the participants.

More interesting is the switch condition: the overall response times in this condition were significantly longer than in the non-switch condition. This effect, also known as switch cost, is known for a long time: naming an item in another language results in longer response latencies because another response code (another target language) must be accessed. Even more interesting is the fact that even in the switch condition, when participants named English items in-between the Dutch prime and target stimuli, a morphological priming effect was obtained. The size of that effect was similar to that yielded in the non-switch condition and the difference between the transparent and opaque condition 
was not significant. That is, the morphological priming effect obtained in Dutch was replicated with Dutch-English bilinguals naming English items in between.

This result does not match the prediction made based on the inhibitory control model. Either the prime survived the active inhibition or there is no active inhibition of the non-target language. Other researchers, Hermans, Bongaerts, De Bot, and Schreuder, (1998) and Costa, Miozzo, and Caramazza (1999), for instance, have suggested that words activated in both languages compete for selection. However, one may want to argue that Verdonschot et al. (2012) did not really test bilingualism because participants still named targets in their first language, even in the switch blocks.

Therefore, Lensink, Verdonschot, and Schiller (2014) tested Dutch-English bilinguals naming targets in their second language. That is, both in the non-switch and in the switch condition, target pictures were named in English, the participants' second language. For instance, the morphologically transparent prime moonlight and the opaque prime honeymoon were compared to the unrelated condition earring with respect to their effect on the naming latencies of the target moon. In the non-switch condition, when all items were in English, the transparent and the opaque condition yielded significant morphological priming, that is, faster processing in the order of $30 \mathrm{~ms}$. Moreover, in the non-switch (but not in the switch) condition, a reduced N400 effect was obtained for the morphologically related compared to the unrelated condition in the time window 400-575 ms after the onset of the target picture. That is, Lensink et al. replicated the morphological priming effect with long lags in bilinguals' second language. Although there was no principled reason to expect that the priming effect would disappear in participants' L2, it is important to demonstrate that it is present in the L2 as well to prove the generalizability of the effect and to demonstrate that language processing is not language-specific.

The results from the switch condition are more interesting. Again, naming latencies increased significantly as a result of switching. However, a significant morphological priming effect was obtained in the switch condition as well. Again, no differences were obtained between the transparent and the opaque condition, neither in the non-switch nor in the switch condition. Thus, the effect in the switch condition tested by Verdonschot et al. (2012) was replicated by Lensink et al. (2014) using different materials and people. Again, there is no evidence that an inhibitory control system actively inhibits the non-target language-at least not to an extent that the effect of morphological priming is dissolved.

In summary, data has been reported from four independent studies so far, including both L1 and L2 production of compounds, that showed significant morphological priming effects both from transparent and opaque primes compared to an unrelated condition. This emphasizes the stability of the morphological priming effect and its generalizability. In the next study described here, we will see whether or not the effect also generalizes to newly acquired compounds. 


\subsubsection{Compound Production: Existing Versus Newly Acquired Items}

So far, I have reported converging evidence that speakers represent the constituting morphemes of a polymorphemic word separately, and that in speaking, these separate morpheme representations are activated. However, how do we learn such polymorphemic words? There are at least two possibilities: either we learn complex words as a whole and gradually decompose them into their constituents or they are in fact acquired as separate morphemes and gradually bind together.

Kaczer, Timmer, Bavassi, and Schiller (2015) employed the long-lag priming task to investigate this question. They taught native Dutch speakers new compounds on the basis of definitions. For instance, participants would learn that "a face that is apple-shaped" is called an apple face, that is, appelgezicht in Dutch. Note that appelgezicht is not an existing word in Dutch, it is a novel compound. Participants learned 36 of these novel compounds. After this learning phase, participants were presented with a long-lag priming task and named 36 target pictures under three conditions: targets (e.g., appel 'apple') were preceded by a familiar, morphologically transparent compound (e.g., appelmoes 'apple sauce') or by a novel, morphologically transparent compound (e.g., appelgezicht 'apple face'), or by an unrelated familiar compound (e.g., kruidnagel 'clove'). As in the experiments by Koester and Schiller $(2008,2011)$, the morphological overlap varied between the modifier (first morpheme in the compound) and the head (second morpheme in the compound). Kaczer et al. (2015) measured naming responses of the target pictures as well as the corresponding event-related brain potentials (ERPs).

Immediately after the learning phase, participants exhibited significant morphological priming effects for the familiar compounds. Although the effect was smaller than in the experiments described in Koester and Schiller $(2008,2011)$, it was statistically reliable. This is the fifth replication of the morphological priming effect with different materials and different participants. However, what happens in the novel compound condition? If these novel compounds are learned as separate morphemes and then bind together, one would expect a priming effect as well. However, if they are learned as a holistic unit that is gradually decomposed, then we may expect to see the absence of a morphological priming effect. Kaczer et al. (2015) observed a strong and significant morphological priming effect in the novel compound condition. In fact, statistical analyses demonstrated that the effect was stronger in the novel compound condition than in the familiar compound condition, possibly because the individual morphemes were still very salient. However, when the same participants were tested with the same materials two days later, that is, after some memory reconsolidation had taken place and novel compounds were learned to some extent, the difference between the familiar and the novel compounds was no longer significant, although both conditions still yielded a morphological priming effect. The ERP effects basically mirrored the behavioral effects, that is, reduced N400 components for the morphologically related as compared to the unrelated condition. 


\subsubsection{Compound Production: Production to Production Priming}

It may be argued that the five studies discussed so far do not exclusively say something about language production because there are also language comprehension processes involved. In all these studies (i.e., Koester \& Schiller, 2008, 2011; Kaczer et al., 2015; Lensink et al., 2014; Verdonschot et al., 2012) the primes were written compound words that were read aloud and showed a priming effect on the naming latencies of morphologically related target pictures. It is true that word reading, even reading aloud, includes language comprehension processes. Therefore, strictly speaking, one may argue that the studies mentioned cannot make the claim that the morphological priming effect is a production effect. It may be the case that the effect is (partially) due to comprehension processing. For instance, it is well known and established that we morphologically decompose words very quickly when we read (Rastle, Davis, \& New, 2004; Taft, 1979, 1981; Taft $\&$ Forster, 1975). Activated morphemes at the comprehension level may activate the corresponding morphemes at the production level and yield priming. For instance, when the compound word prime moonshine is read aloud, both moon and shine may become activated. When the target picture moon is to be named a little later, it may benefit from that previous activation. However, it does not mean that the morpheme moon has become activated due to a production process per se. The origin of the priming effect may in fact be located on the language comprehension level.

To investigate this question, Lensink, Verdonschot, and Schiller (FORTHCOMING) modified the long-lag priming paradigm slightly. Instead of compound words as primes (and monomorphemic words as fillers), only pictures were presented in this study. That is, native Dutch participants were engaged in a picture naming experiment with a long-lag priming design. For instance, participants named the picture of a zwaardvis ('swordfish'), then they named 7-9 other pictures (fillers, targets, and primes) before they were presented with a picture of a zwaard ('sword'). Naming latencies to target pictures (e.g., zwaard) preceded by morphologically related primes (e.g., zwaardvis) were compared to an unrelated condition. All primes were morphologically transparent.

Response latencies to target pictures were significantly faster when preceded by morphologically related prime pictures as compared to unrelated pictures. This finding replicates earlier results and confirms the claim that the morphological priming effect is a genuine speech production effect. That is, the naming of the prime picture zwaardvis made the activation and retrieval of the corresponding morphemes zwaard and vis necessary. When the target picture $z$ waard was to be named, the morpheme $z$ waard was already pre-activated and therefore naming was facilitated. Since there were no comprehension processes involved in this experimental set-up, the obtained morphological priming effect must have its origin in the production system. Lüttmann, Zwitserlood, Böhl, and Bölte (2011) suggested that during compound production a single lemma node becomes activated. At the form level of representation, morphological composition of the constituting morphemes takes place. Presumably, it is at this level that the morphological priming effect takes place due to the explicit representation of morphemic relationships in the lexicon (Napps, 1989). 


\section{Summary and Conclusion}

In this article, a number of psycho- and neurolinguistic studies have been reviewed that bear on the processing of morphologically complex words in word production. For instance, how do we produce words like Sonntagnachmittagsspaziergang? One of the issues regarding this question concerns the representation of complex words: are they stored in their whole form in the lexicon or rather in decomposed form, morpheme by morpheme? The six studies on compound production reviewed in this article seem to suggest that complex words are computed by putting the constituting morphemes together. In each study, there is evidence for the activation of the individual morphemes of compound words as reflected by morphological priming effects. This supports full-parsing accounts rather than full-listing accounts of representation. Furthermore, some of the studies have also provided electrophysiological evidence for reduced N400 effects related to target word processing in morphologically primed as compared to unrelated conditions. Moreover, functional neuroimaging evidence for activity in BA 47 seems to reflect enhanced processing resources in morphologically-primed relative to unrelated conditions, which may lead to faster processing reflected behaviorally (by faster naming latencies of the targets) and electrophysiologically (by reduced N400 effects). These studies also support the claim that morphological processing may be an independent process during language production.

\section{Suggestions for Future Research}

There are, however, still some unresolved issues that ask for future research. For instance, it has been clearly shown that morphological priming lasts longer than either semantic or phonological priming; however, it is not exactly clear why this is the case. Furthermore, how long the morphological priming effect lasts is not known either. So far, intervals between 7 and 10 trials have been tested and significant priming effects have been obtained. However, it is not known how long the effect will last, and it is unlikely that there is no upper limit. Establishing the exact interval of morphological priming may further help to characterize the nature of the effect.

The study by Lensink et al. (FORTHCOMING) demonstrates that the morphological priming effect is a production effect proper. However, the magnitude of the morphological priming effect was smaller than in most previous studies. Although the effect was still significant and comparable to some earlier effects (for instance, the magnitude of the priming effect in Koester and Schiller, 2008, set 2 or the priming effect for familiar compounds in Kaczer et al., 2015), it may still be the case that there is a contribution from comprehension as well, and it would be most relevant to investigate this contribution because it would help understand the exact organization of the mental lexicon and the interaction between the comprehension and the production lexicon. 


\section{References}

Bien, H., Levelt, W. J. M., \& Baayen, R. H. (2005). Frequency effects in compound production. Proceedings of the National Academy of Sciences, 102, 17876-17881.

Bozic, M., \& Marslen-Wilson, W. (2010). Neurocognitive contexts for morphological complexity: Dissociating inflection and derivation. Language and Linguistics Compass, 11 , 1063-1073.

Butterworth, B. (1983). Lexical representation. In B. Butterworth (Ed.), Language production (Vol. 2, pp. 257-294). San Diego, CA: Academic Press.

Butterworth, B. (1989). Lexical access in speech production. In W. Marslen-Wilson (Ed.), Lexical representation and process (pp. 108-135). Cambridge, MA: MIT Press.

Caramazza, A. (1997). How many levels of processing are there in lexical access? Cognitive Neuropsychology, 14, 177-208.

Caramazza, A., \& Miceli, G. (1990). The structure of graphemic representations. Cognition, 37, 243-297.

Clahsen, H. (1999). Lexical entries and rules of language: A multidisciplinary study of German inflection. Behavioral and Brain Sciences, 22, 991-1060.

Costa, A., Miozzo, M., \& Caramazza, A. (1999). Lexical selection in bilinguals: Do words in the bilingual's two lexicons compete for selection? Journal of Memory and Language, $41,365-397$.

De Zubicaray, G. I., \& Schiller, N. O. (2019). The Oxford handbook of neurolinguistics. Oxford, U.K.: Oxford University Press.

Dell, G. S. (1986). A spreading-activation theory of retrieval in sentence production. Psychological Review, 93, 283-321.

Dell, G. S. (1988). The retrieval of phonological forms in production: Tests of predictions from a connectionist model. Journal of Memory and Language, 27, 124-142.

Dohmes, P., Zwitserlood, P., \& Bölte, J. (2004). The impact of semantic transparency of morphologically complex words on picture naming. Brain and Language, 90, 203-212.

Feldman, L. B. (2000). Are morphological effects distinguishable from the effects of shared meaning and shared form? Journal of Experimental Psychology: Learning, Memory and Cognition, 26, 1431-1444.

Fiorentino, R., Naito-Billen, Y., Bost, J., \& Fund-Reznicek, E. (2014). Electrophysiological evidence for the morpheme-based combinatoric processing of English compounds, Cognitive Neuropsychology, 31, 123-146. 
Fiorentino, R., \& Poeppel, D. (2007). Compound words and structure in the lexicon. Language and Cognitive Processes, 22, 953-1000.

Fromkin, V. A. (1971). The non-anomalous nature of anomalous utterances. Language, 47, 27-52.

Garrett, M. F. (1975). The analysis of sentence production. In G. H. Bower (Ed.), The psychology of learning and motivation: Vol. 9. Advances in research and theory (pp. 133177). New York, NY: Academic Press.

Garrett, M. F. (1980). Levels of processing in sentence production. In B. Butterworth (Ed.), Language production: Vol. 1. Speech and talk (pp. 177-220). London, U.K.: Academic Press.

Green, D. W. (1998). Mental control of the bilingual lexico-semantic system. Bilingualism: Language and Cognition, 1, 67-81.

Grosjean, F. (2010). Bilingual: Life and reality. Cambridge, MA: Harvard University Press.

Gumnior, H., Bölte, J., \& Zwitserlood, P. (2006). A chatterbox is a box: Morphology in German word production. Language and Cognitive Processes, 21, 920-944.

Heim, S., \& Specht, K. (2019). Studying language with functional Magnetic Resonance Imaging (fMRI). In G. I. de Zubicaray \& N. O. Schiller (Eds.), The Oxford handbook of neurolinguistics (pp. 72-93). Oxford, U.K.: Oxford University Press.

Hermans, D., Bongaerts, T., De Bot, K., \& Schreuder, R. (1998). Producing words in a foreign language: Can speakers prevent interference from their first language? Bilingualism: Language and Cognition, 1(3), 213-229.

Indefrey, P. (2011). The spatial and temporal signatures of word production components: A critical update. Frontiers in Psychology, 2, 255.

Indefrey, P., \& Levelt, W. J. M. (2004). The spatial and temporal signatures of word production components. Cognition, 92, 101-144.

Isel F., Gunter T. C., \& Friederici, A. D. (2003). Prosody-assisted head-driven access to spoken German compounds. Journal of Experimental Psychology: Learning, Memory, and Cognition, 29, 277-288.

Janssen, N., Bi, Y., \& Caramazza, A. (2008). A tale of two frequencies: Determining the speed of lexical access in Mandarin Chinese and English compounds. Language and Cognitive Processes, 23, 1191-1223.

Kaczer, L., Timmer, K., Bavassi, L., \& Schiller, N. O. (2015). Long-lag priming effects of novel and existing compounds on naming familiar objects reflect memory consolidation processes: A combined behavioral and ERP study. Brain Research, 1629, 309-317. 
Kielar, A., \& Joanisse, M. F. (2011). The role of semantic and phonological factors in word recognition: An ERP cross-modal priming study of derivational morphology. Neuropsychologia, 49, 161-177.

Koester, D., Gunter, T. C., \& Wagner, S. (2007). The morphosyntactic decomposition and semantic composition of German compound words investigated by ERPs. Brain and Language, 102, 64-79.

Koester, D., Gunter, T. C., Wagner, S., \& Friederici, A. D. (2004). Morphosyntax, prosody, and linking elements: The auditory processing of German nominal compounds. Journal of Cognitive Neuroscience, 16, 1647-1668.

Koester, D., \& Schiller, N. O. (2008). Morphological priming in overt language production: Electrophysiological evidence from Dutch. NeuroImage, 42, 1622-1630.

Koester, D., \& Schiller, N. O. (2011). The functional neuroanatomy of morphology in language production. NeuroImage, 55, 732-741.

Kolan, L., Leikin, M., \& Zwitserlood, P. (2011). Morphological processing and lexical access in speech production in Hebrew: Evidence from picture-word interference. Journal of Memory and Language, 65, 286-298.

Kutas, M., \& Hillyard, S. A. (1980). Reading senseless sentences: Brain potentials reflect semantic incongruity. Science, 207, 203-205.

Kutas, M., \& Hillyard, S. A. (1984). Brain potentials reflect word expectancy and semantic association during reading. Nature, 307, 161-163.

Leckey, M., \& Federmeier, K. D. (2019). Electrophysiological methods in the study of language processing. In G. I. de Zubicaray \& N. O. Schiller (Eds.), The Oxford handbook of neurolinguistics (pp. 42-71). Oxford, U.K.: Oxford University Press.

Lensink, S. E., Verdonschot, R. G., \& Schiller, N. O. (2014). Morphological priming during language switching: An ERP study. Frontiers in Human Neuroscience, 8, 995.

Lensink, S. E., Verdonschot, R. G., \& Schiller, N. O. (forthcoming). Morphological processing in language production: Evidence from picture-picture priming.

Levelt, W. J. M. (1989). Speaking: From intention to articulation. Cambridge, MA: MIT Press.

Levelt, W. J. M., Roelofs, A., \& Meyer, A. S. (1999). A theory of lexical access in speech production. Behavioral and Brain Sciences, 22, 1-75.

Libben, G. (2006). Why study compound processing? An overview of the issues. In G. Libben \& G. Jarema (Eds.), The representation and processing of compound words. New York, NY: Oxford University Press. 
Lüttmann, H., Zwitserlood, P., Böhl, A., \& Bölte, J. (2011). Evidence for morphological composition at the form level in speech production. Journal of Cognitive Psychology, 23, 818-836.

Mannelis, L., \& Tharp, D. (1977). The processing of affixed words. Memory and Cognition, 5, 690-695.

Marslen-Wilson, W., Tyler, L. K., Waksler, R., \& Older, L. (1994). Morphology and meaning in the English mental lexicon. Psychological Review, 101, 3-33.

Meyer, A. S. (1990). The time course of phonological encoding in language production: The encoding of successive syllables of a word. Journal of Memory and Language, 29, 524-545.

Meyer, A. S. (1991). The time course of phonological encoding in language production: Phonological encoding inside a syllable. Journal of Memory and Language, 30, 69-89.

Milin, P., Feldman, L. B., Ramscar, M., Hendrix, P., \& Baayen, R. H. (2017). Discrimination in lexical decision. PLoS ONE, 12, e0171935.

Napps, S. E. (1989). Morphemic relationships in the lexicon: Are they distinct from semantic and formal relationships? Memory and Cognition, 17, 729-739.

Nichols, T., Brett, M., Andersson, J., Wager, T., \& Poline, J. (2005). Valid conjunction inference with the minimum statistic. NeuroImage, 25, 653-660.

Penke, M., Weyerts, H., Gross, M., Zander, E., Münte, T. F., \& Clahsen, H. (1997). How the brain processes complex words: An ERP-study of regular and German verb inflections. Cognitive Brain Research, 6, 37-52.

Pinker, S. (1999). Words and rules: The ingredients of human language. New York, NY: Harper Collins.

Price, C. J., \& Friston, K. J. (1997). Cognitive conjunction: A new approach to brain activation experiments. NeuroImage, 5, 261-270.

Rastle, K., Davis, M. H., \& New, B. (2004). The broth in my brother's brothel: Morpho-orthographic segmentation in visual word recognition. Psychonomic Bulletin \& Review, 11, 1090-1098.

Rodriguez-Fornells, A., Clahsen, H., Lleó, C., Zaake, W., \& Münte, T. F. (2001). Event-related brain responses to morphological violations in Catalan. Cognitive Brain Research, $11,47-58$.

Roelofs, A. (1996). Serial order in planning the production of successive morphemes of a word. Journal of Memory and Language, 35, 854-876.

Schiller, N. O., Greenhall, J. A., Shelton, J. R., \& Caramazza, A. (2001). Serial order effects in spelling errors: Evidence from two dysgraphic patients. Neurocase, 7, 1-14. 
Schiller, N. O., \& Verdonschot, R. G. (2015). Accessing words from the mental lexicon. In J. R. Taylor (Ed.), The Oxford handbook of the word (pp. 161-190). Oxford, U.K.: Oxford University Press.

Schiller, N. O., \& Verdonschot, R. G. (2019). Morphological theory and neurolinguistics. In J. Audring \& F. Masini (Eds.), The Oxford handbook of morphological theory (pp. 554572). Oxford, U.K.: Oxford University Press.

Schreuder, R., Grendel, M., Poulisse, N., Roelofs, A., \& Van de Voort, M. (1990). Lexical processing, morphological complexity and reading. In D. A. Balota, G. B. Flores d'Arcais, \& K. Rayner (Eds.), Comprehension processes in reading (pp. 125-141). Hillsdale, NJ: Lawrence Erlbaum.

Seidenberg, M. S., \& Gonnerman, L. M. (2000). Explaining derivational morphology as the convergence of codes. Trends in Cognitive Sciences, 4, 353-361.

Smolka, E., Gondan, M., \& Rösler, F. (2015). Take a stand on understanding: Electrophysiological evidence for stem access in German complex verbs. Frontiers in Human Neuroscience, 9,62 .

Smolka, E., Khader, P. H., Wiese, R., Zwitserlood, P., \& Rösler, F. (2013). Electrophysiological evidence for the continuous processing of linguistic categories of regular and irregular verb inflection in German. Journal of Cognitive Neuroscience, 25, 1284-1304.

Spalek, K., \& Thompson-Schill, S. (2008). Task-dependent semantic interference in language production: An fMRI study. Brain and Language, 107, 220-228.

Stemberger, J. P. (1985). The lexicon in a model of language production. New York, NY: Garland.

Stockall, L., \& Marantz, A. (2006). A single-route, full-decomposition model of morphological complexity: MEG evidence. Mental Lexicon, 1, 85-123.

Taft, M. (1979). Recognition of affixed words and the word frequency effect. Memory and Cognition, 7, 263-272.

Taft, M. (1981). Prefix stripping revisited. Journal of Verbal Learning and Verbal Behavior, 20, 289-297.

Taft, M. (2004). Morphological decomposition and the reverse base frequency effect. Quarterly Journal of Experimental Psychology, 57A, 745-765.

Taft, M., \& Forster, K. (1975). Lexical storage and retrieval of prefixed words. Journal of Verbal Learning and Verbal Behavior, 14, 638-647.

Tyler, L. K., Marslen-Wilson, W. D., \& Waksler, R. (1993). Representation and access of derived words in English. In Cognitive models of speech processing: The second Sperlonga meeting (pp. 125-140). Hove, U.K.: Lawrence Erlbaum. 
Verdonschot, R. G., Middelburg, R., Lensink, S. E., \& Schiller, N. O. (2012). Morphological priming survives a language switch. Cognition, 124, 343-349.

Zwitserlood, P., Bölte, J., \& Dohmes, P.(2000). Morphological effects on speech production: Evidence from picture naming. Language and Cognitive Processes, 15, 563-591.

Zwitserlood, P., Bölte, J., \& Dohmes, P.(2002). Where and how morphologically complex words interplay with naming pictures. Brain and Language, 81, 358-367.

\section{Niels O. Schiller}

Department of Linguistics, Leiden University 